and Rhabditis oxycerca are saprophages. In Diplogaster, food particles are sucked in by the expansion of the tri-radiate lumen of the corpus (first bulb), which acts rather like a pipette. The lumen through the base of the corpus can be closed completely and acts as a valve. From the first bulb, food is transferred through the isthmus and second bulb by a wave of peristaltic-like action caused by successive contractions of the radial muscles surrounding the tri-radiate lumen of both parts. In $P$. lambdiensis and $R$. oxycerca the second bulb has threo equally spaced valve plates which move backwards into a cup-like cavity. The whole process of feeding is very complex, but appears to be divisible into the following stages: (a) the procorpus and corpus open, drawing in food and, on closing, food collects in the forepart of the isthmus; (b) this food mass is carried further back to the valve by a wave of 'peristalsis'; (c) the cup behind the valve dilates, sucking the food through the valve flaps, which then flick back into the cup togethor with the whole of the anterior part of the valve; $(d)$ the cup collapses, forcing the food into the osophago-intestinal canal behind it, this canal also showing 'peristaltic' dilation and collapse.

Dr. H. R. Wallace (Rothamsted), in discussing "Plant Roaction to Parasitism by Nematodes" listed some of these reactions: he mentioned round. ing of cells and loosening from one enother, possibly by the action of pectic enzymes in tissues attacked by Ditylenchus dipsaci; the formation of giant cells in roots attackod by Heterodera spp. and Meloidogyne spp., possibly indicating the presence of growth hormones; cell hyperplasia and hyportrophy in roots attacked by Radopholus similis, and extensive necrosis associated with the invasion of roots by Pratylenchus spp. He wont on to describe his work on the attack in chrysanthemum leaves by Aphelenchoides ritzemabosi. In susceptible varieties few cells appoar to be attacked, the nematodes remain very near their point of entry, and reproduction goes on; but in rosistant varieties many cells are attackod, the nematodes move far and wide and there is almost no reproduction. Resistant varieties show rapid and extensivo leaf discoloration associated with the enzymic oxidation of plant polyphenols, and it is suggested that thero is an absence of some nutritional factor in these leaves. Dr. Wallace ended by stressing the state of our ignorance of the inter-relationships, particularly biochemical ones, of nematode parasite and plant.

Dr. R. S. Pitcher (East Malling Research Station) spoke on "Nematode Vectors of Virus Diseases", and said that it was the pioneer work of Hewitt and Raski in California that first showed the transmission of virus by nematodes. He stressed that though this work is important in its own right, it should also stimulate study of the complex inter-rolationships of nematodes and other 'soil inhabiting' pathogens and their relation to the plant and its environment. Of the 'soil-borne' viruses, those that have been transmitted by nematodes could be classified as having infectivity destroyed by air-drying of soil, and while 'tobacco rattle', which is transmitted by Trichodorus pachydermus, has rod-shaped particles, the others have isometric particles, for example, 'fanleaf of grape', 'peach yellow bud mosaic' and 'arabis mosaic' transmitted by Xiphinema index, $X$. americanum and $X$. diversicaudatum respectively and 'tomato black ring' transmitted by Longidorus elongatus. There is a clear correlation of disease and the presence of nematodes which are all members of the Dorylaimoidea, with relatively long spears when compared with most members of the Tylenchida, none of which is known as a virus vector. The means by which virus transmission takes place is unknown and, as yet, a matter for speculation.

"Practical Problems and Recent Trends in Nema. tode Control" was the topic chosen by Mr. F. C. Peacock (Plant Protection, Ltd., Jealott's Hill), who said that many of the earliest nematicides which still give good service are halogenated hydrocarbons. They are generally phytotoxic and relatively volatile substances. Methyl bromide and D-D are early examples and 1,2-dibromo-3-chloropropane a more recont one. A second group of nematicides are the organic phosphates: parathion has been used for some years; more recent examples are 0-2,4-dichlorophenyl-, O-diethyl phosphorothioate and diethyl pyrazinyl phosphorothioate. This group of com. pounds is non-volatile and relatively insoluble in water, but has high nematicidal and residual value and low phytotoxicity, albeit high mammalian toxicity. Dithiocarbamates make good soil sterilants but have high phytotoxicity; their action against nematodes is said to be due to the breakdown product methyl isothiocyanate. Various sulphur compounds, such as chlorophenyl methyl rhodanine, have high phytotoxicity which is useful in seed-bed preparation, but the tetrahydrothiophene dioxides and trithiophene (occurring in Tagetes erecta) have low phytotoxicity. Recently the use of yellow oxide of mercury incorporated in soil has shown promise. The observation that a glycoside from Asparagus officinalis roots inhibits nematode attack has led to an investigation of the systemic use of maleic hydrazide and other substances, applied to leaves to prevent attack on roots either by the exudation of toxic material or the inhibition of attractive diffusates, or theoretically the preferable killing of already established parasitic nematodes. Mr. Peacock finished by stressing the noed for good husbandry so that nematicides are only supplementary in function, and the need for recognizing that different nematode diseases need treatment by different nematicides.

\section{J. B. GOODEY}

\title{
AREA OF RESIDENCE OF MENTAL HOSPITAL PATIENTS
}

$\mathrm{O}^{\mathrm{m}}$ WE of the Registrar General's series of studies on medical and population subjects contains detailed statistics about the areas from which patients were admitted to mental hospitals in England and Wales during 1957. (Studies on Medical and Population Subjects, No. 16; "Aroa of Rosidence of Mental Hospital Patients", H.M.S.O. 15s. 6d. net.)
The addresses of patients at the time of admission. have been classified according to the administrative areas in which they are situatod. Separate tables are given showing, for the first time, the numbers of admissions from oach county borough and administra. tive county and from each motropolitan borough in the County of London. Figures are given separately 
for each sex and for certain age-groups and diagnoses.

Total admissions to mental hospitals during 1957 numbered 88,943 , of which 48,266 (or 54 per cent) related to patients admitted to a mental hospital for the first time. Separate figures are given for total admissions (that is, first admissions and all re-admissions) and first admissions from each area and com. parisons can be made on either basis. Most of the figures which follow are based on the total number of admissions and not on the number of persons admitted and do not therefore necessarily reflect differences in the proportion of persons in an area who were admitted to a mental hospital during the year.

Of the total number of admissions, 6,859 came from the County of London, while admissions from the counties of Middlesex, Kent, Essex, Surrey and Hertfordshire numbered 4,722, 3,674, 4,054, 3,214 and 1,571 respectively, giving a total of 24,094 for Jundon and the surrounding counties. Among the counties outside Greater London, the highest numbers of admissions were of residents in Lancashire $(2,947)$, and the West Riding of Yorkshire $(2,395)$.

Although the volume only contains figures of the numbers of admissions, it is possible to relate these figures to the estimated populations of the areas at June 30, 1957, to give admission-rates per 1,000 population. The ten county boroughs with the highest number of admissions, with the corresponding admission-rates per 1,000 of the resident population, were as follows :

$\begin{array}{lrll}\text { Birmingham } & 2,096(1 \cdot 9) & \text { Sheffield } & 812(1 \cdot 6) \\ \text { Leeds } & 1,023(2 \cdot 0) & \text { Cardiff } & 761(3 \cdot 0) \\ \text { Liverpool } & 1,005(1 \cdot 3) & \text { Stoke-on-Trent } & 735(2 \cdot 7) \\ \text { Manchester } & 836(1 \cdot 2) & \text { Kingston upon Hull } & 702(2 \cdot 3) \\ \text { Bristol } & 823(1 \cdot 9) & \text { Bradford } & 622(2 \cdot 2)\end{array}$

Admission-rates for Lancashire and the West Riding of Yorkshire were 1.4 and 1.5 per 1,000 respectively.

Among individual metropolitan boroughs of London those having the highest rates of admission were Stoke Newington with $2 \cdot 19$ (144 admissions) per
1,000 and Stepney and Chelsea both with $2 \cdot 8$ per 1,000 of the population (274 and 144 admissions respectively).

The higher rates of admission are not concentrated in those counties with a greater degree of industrialization. For example, the rates for Staffordshire and Durham were $1 \cdot 7$ and $1 \cdot 6$ compared with $2 \cdot 5$ and $2 \cdot 1$ per 1,000 of the population, respectively, for Cornwall and Norfolk.

There were 1,553 admissions of patients stated to have no fixed abode, or 1.7 per cent of the total number admitted. Among these the number of re-admissions was 913 or 59 per cent, a figure well above the national percentage of 46 . The admissions of patients normally resident outside England and Wales numbered 188 or 0.2 per cent of the total number of admissions.

Among the causes of admission, manic-depressive reaction contributed the largest, proportion for England and Wales as a whole. Of the national total of 4,868 admissions due to character, behaviour and intelligence disorders, 440 were from the County of London and a further 322 were of people with no fixed abode. In London, 1,954 out of the 6,859 admissions resulted from schizophrenia (28 per cent) and 30 per cent were for manic-depressive reaction.

The proportions due to schizophrenia among the admissions from the ten county boroughs shown above were :

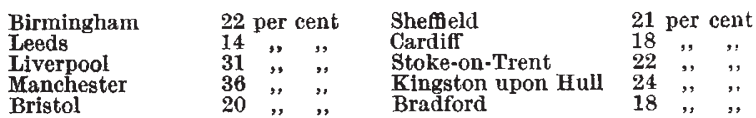

By comparison, the proportions due to schizophrenia among the admissions from the predominantly rural counties of Cornwall and Herefordshire were 11 and 9 per cent respectively.

Of the first admissions for the whole country, 6,906 were reported as due to schizophrenia (14 per cent) compared with 13,902 admissions or 29 per cent for manic-depressive reaction.

\section{COMMUNITY MENTAL HEALTH}

$\mathrm{W}$ ITH the aid of a generous grant from the Nuffield Provincial Hospitals Trust, Political and Economic Planning has recently begun a threeyear study of the mental health services of Britain with particular emphasis on the subject of community care. The work is under the control of a steering group, the director of research being Dr. F. M. Martin, of the University of Edinburgh. A broadsheet, entitled "Community Mental Health Services", gives a general background to the work and shows why, and in what directions, research is necessary*.

The greater part of the research programme of Political and Economic Planning will take the form of a study of the actual operation of community mental health services in selected areas. Districts will be chosen for study primarily because they have already developed distinctive and interesting patterns of community care, such as might prove models for other areas. It is hoped that, in at least some areas, it will be possible to work in association with locally

* Planning, 26, No. 447 (12 December, 1960): "Community Mental Health Services". Pp. 337--356. (London: Political and Economic Planning, 1960.) $2 s .6 d$. based research workers who are already interested or actively concerned in the study of mental health services. An assessment of a particular form of organization of services must take account of the statistics of patient movernent, but these cannot be adequately evaluated in isolation. It will be particularly important to make some estimate of the social and personal consequences for patients and their families, of different patterns of care, and to study closely the nature of the community services provided.

In view of the wide variety of workers likely to be engaged in community care, and of the contradictory views which have been expressed on their place in the mental health services, it would be of interest to attempt some systematic analysis of the work actually performed by health visitors, psychiatric social workers, mental welfare officers, and so on. In this way it should be possible to set an analysis of professional functions against an analysis of the needs of patients and families, and to consider how effectively they can be related to one another. A comprehensive area study should also take account 